\title{
A Novel APProach to Estimate the Distribution, Density AND AT-SEA Risks OF A
} Centrally-Placed Mobile Marine Vertebrate

Stephen K. Pikesley ${ }^{a, b}$, Pierre Didier Agamboue ${ }^{c}$, Jean Pierre Bayet ${ }^{d}$, Jean Noel Bibang e, Eric Augowet Bonguno ${ }^{\mathrm{f}}$, François Boussamba ${ }^{\mathrm{g}}$, Annette C. Broderick ${ }^{\mathrm{a}}$, Michael S. Coyne ${ }^{\mathrm{a}, \mathrm{h}}$, Philippe Du Plessis ${ }^{\mathrm{i}}$, François Edgard Faure ${ }^{\mathrm{j}}$, J. Michael Fay ${ }^{\mathrm{e}}$, Angela Formia ${ }^{\mathrm{c}}$, Brendan J. Godley a,b, Judicael Regis Kema Kema ${ }^{k}$, Brice Didier Koumba Mabert ${ }^{\mathrm{j}}$, Jean Churley Manfoumbi d, Georges Mba Asseko e, Kristian Metcalfe a, Gianna Minton k, Sarah Nelms a, Solange Ngouessono ${ }^{\mathrm{f}}$, Jacob Nzegoue ${ }^{\mathrm{c}}$, Carole Ogandanga ${ }^{1}$, Carmen Karen Kouerey Oliwina c, Franck Otsagha ${ }^{\text {e }}$, Richard J. Parnell c , Micheline Schummer Gnandji ${ }^{1}$, Guy-Philippe Sounguet ${ }^{\mathrm{f}}$, Mesmin Wada ${ }^{1}$, Lee White ${ }^{\mathrm{f}}$, $\&$ *Matthew J. Witt ${ }^{\mathrm{b}}$

\section{Addresses:}

${ }^{a}$ Centre for Ecology and Conservation, University of Exeter. Cornwall. UK

${ }^{\mathrm{b}}$ Environment and Sustainability Institute, University of Exeter. Cornwall. UK

${ }^{\mathrm{c}}$ Wildlife Conservation Society, Global Conservation Program, 2300 Southern Blvd., Bronx, NY 10460. USA

d IBONGA-ACPE, BP 148, Gamba. Gabon

e Agence Nationale des Pêches et de l'Aquaculture, BP 20484, Libreville. Gabon

${ }^{\mathrm{f}}$ Agence Nationale des Parcs Nationaux, BP 20379, Libreville. Gabon

${ }^{\mathrm{g}}$ Aventures Sans Frontières, BP 7248, Libreville. Gabon

${ }^{\text {h }}$ SEATURTLE.org, Durham, NC. USA

${ }^{i}$ Fondation Liambissi, BP 2924, Port-Gentil. Gabon

${ }^{j}$ CNDIO-Gabon, BP 10961, Libreville. Gabon

${ }^{\mathrm{k}}$ WWF-Gabon, BP 9144, Libreville. Gabon

${ }^{1}$ Direction Générale des Pêches et de l’Aquaculture, BP 9498, Libreville. Gabon 
$28 *$ Corresponding author: Matthew J. Witt, Environment and Sustainability Institute, University

29 of Exeter, Penryn Campus, Cornwall. TR10 9FE, UK. Telephone: 01326 370450, email:

30 M.J.Witt@exeter.ac.uk

31

32 Article type: Research

33 
34 A Novel APProach to Estimate the Distribution, Density AND AT-SEA RiSKs OF A 
Formulating management strategies for mobile marine species is challenging, as knowledge is required of distribution, density, and overlap with putative threats. As a step towards assimilating knowledge, ecological niche models may identify likely suitable habitats for species, but lack the ability to enumerate species densities. Traditionally, this has been catered for by sightings-based distance sampling methods that may have practical and logistical limitations. Here we describe a novel method to estimate at-sea distribution and densities of a marine vertebrate, using historic aerial surveys of Gabonese leatherback turtle (Dermochelys coriacea) nesting beaches and satellite telemetry data of females at sea. We contextualise modelled patterns of distribution with putative threat layers of boat traffic, including fishing vessels and large ship movements, using Vessel Monitoring System (VMS) and Automatic Identification System (AIS) data. We identify key at-sea areas in which protection for internesting leatherback turtles could be considered within the coastal zone of Gabonese Exclusive Economic Zone (EEZ). Our approach offers a holistic technique that merges multiple datasets and methodologies to build a deeper and insightful knowledge base with which to manage known activities at sea. As such, the methodologies presented in this study could be applied to other species of sea turtles for cumulative assessments; and with adaptation, may have utility in defining critical habitats for other central-place foragers such as pinnipeds, or sea bird species. Although our analysis focuses on a single species, we suggest that putative threats identified within this study (fisheries, seismic activity, general shipping) likely apply to other mobile marine vertebrates of conservation concern within Gabonese and central African coastal waters, such as olive ridley sea turtles (Lepidochelys olivacea), humpback dolphins (Sousa teuszii) and humpback whales (Megaptera novaeangliae).

60

61 Keywords: inter-nesting, leatherback turtles, marine protected area (MPA), spatial analysis, Automatic Identification System (AIS), Vessel Monitoring System (VMS) 


\section{INTRODUCTION}

4

Multiple modelling techniques exist to build an understanding of habitat niches for species in the marine environment (Aarts et al., 2008; Edrén et al., 2010; Forney et al., 2015; Matthiopoulos et al., 2004; Pikesley et al., 2014; Wedding et al., 2016). These methods are challenged by the issue of enumerating species densities, which has traditionally relied upon sightings-based distance sampling (Buckland et al., 2001), with data being collected primarily by way of boat or aerial surveys (Aerts et al., 2013; Becker et al., 2014; Hammond et al., 2002). Typically, distance sampling relies on three key assumptions being met (Thomas et al., 2010); species are detected with certainty, species do not move, distance measurements are exact (Thomas et al., 2010). As such, application of distance sampling methodologies to aerial based surveys have helped reveal density patterns across a broad spectrum of marine species 'at sea' (Lauriano et al., 2011; Scheidat et al., 2012; Seminoff et al., 2014) and have also proved their efficacy in enumerating densities of marine species whilst on land (Stapleton et al., 2015). However, many marine species are challenging to observe at sea because of their cryptic nature, spending limited time at the sea surface, or due to restrictions imposed by environmental conditions (weather and sea state) (Evans \& Hammond 2004). To provide for an alternative complementary process to estimate at-sea distributions and relative densities, we formulated a method that was independent of the need to visually sight species at sea, that instead utilised existing available data: aerial surveys of leatherback turtle nest counts and satellite tracking data.

Increased understanding of spatial and temporal habitat use, together with associated densities, may facilitate successful management strategies. However, design, implementation and regulation of protection for mobile marine species is challenging; particularly for far ranging, pelagic and migratory species (Briscoe et al., 2016; Hyrenbach et al., 2000). Defining appropriate spatial and temporal bounds to managed areas is more tractable when animals seasonally aggregate (Maxwell et al., 2014; Whittock et al., 2014; Witt et al., 2008). In 2002, the central African country of Gabon created a system of coastal and terrestrial National Parks 
with the aim of protecting key areas of biodiversity-rich habitats. Thirteen National Parks were designated, including a single marine park to the south of the country at Mayumba (Fig. 1). Gabon's beaches support important nesting sites for sea turtles, including globally important breeding aggregations for the leatherback turtle (Dermochelys coriacea); the Southeast Atlantic Ocean subpopulation is currently listed as IUCN Red List Data Deficient (Tiwari et al., 2013). The northern and southern extremes of the Gabon coast (Pongara and Mayumba National Park) receive the highest densities of nesting activity (Witt et al., 2009). Additionally, the olive ridley (Lepidochelys olivacea), green (Chelonia mydas) and hawksbill sea turtles (Eretmochelys imbricata) also nest (Casale et al., 2017; Maxwell et al., 2011; Metcalfe et al., 2015).

The leatherback turtle is highly migratory with expansive post-nesting dispersal patterns (Fossette et al., 2014; Roe et al., 2014), but will seasonally aggregate off Gabon's nesting beaches. Protection of large scale aggregations likely represents a significant management target within coastal waters (Hitipeuw et al., 2007; Nel et al., 2013; Roe et al., 2014; Witt et al., 2008). However, for protection to be effective, density and distributions of turtles need to be ascertained and relevant threats identified, and if possible quantified, preferably in space and time. In the marine environment, sea turtles may negatively interact with a broad suite of vessel activity. These interactions can lead to bycatch from coastal (Alfaro-Shigueto et al., 2007; Lum, 2006; Witt et al., 2011) and oceanic (Huang, 2015; Lewison et al., 2004) fisheries, boat strike (Denkinger et al., 2013; Nabavi et al., 2012), crude oil contamination (Follett et al., 2014), or possible displacement from critical habitats or auditory damage from seismic surveying (Nelms et al., 2016). Within Gabon's territorial waters bycatch from fisheries (Casale et al., 2017) and/or boat strike (Billes et al., 2003) may negatively impact leatherback turtles. There is also extensive offshore petrochemical extraction primarily located to the south of Port Gentil (http://www.seaturtle.org/mtrg/projects/gabon/MarineAtlas.pdf).

At-sea vessel activity may be gathered by both Vessel Monitoring System (VMS) and Automatic Identification System (AIS) data. The use of VMS, primarily as a tool for providing at-sea densities of fisheries (Hintzen et al., 2012; Vermard et al., 2010; Witt and Godley, 2007) has revolutionised the process of mapping, analysing and interpreting fisheries activity patterns. 
119 The advent of AIS may prove to provide additional capabilities due to time resolution of data

120 (Natale et al., 2015) and inclusion of multiple vessel types (Shelmerdine, 2015). The installation

121 and operation of VMS is discretional among maritime nations; the requirement to fit AIS

122 systems is, however, mandatory aboard vessels making international voyages with gross

123 tonnage $\geq 300 \mathrm{t}$, cargo vessels $\geq 500 \mathrm{t}$ and all passenger ships regardless of size (Shelmerdine,

124 2015).

125 In this study, we combine aerial survey nest count data for leatherback turtles together

126 with satellite telemetry data from nesting females and contextualise these with VMS and AIS

127 data. Our aims were to: (i) model leatherback turtle distribution and relative density at sea using

128 a method that was independent of the need to sight species at sea, (ii) investigate areas of spatial

129 overlap between leatherback turtles and putative threats from vessels associated with multiple

130 industry categories, and (iii) identify key areas for inter-nesting leatherbacks within the

131 Gabonese Exclusive Economic Zone (EEZ) that may benefit from application of Marine

132 Protected Areas (MPAs).

133

2. METHODS

\subsection{Aerial survey data}

Aerial surveys were flown along the Gabonese coast using a variety of high-wing light aircraft (Supplementary Material, Table A.1) as described in (Pikesley et al., 2013). Surveys were organised to coincide with the main period of leatherback turtle nesting activity

141 (December-February; (Witt et al., 2009)). Multiple surveys were conducted in 2002/03 $(n=2)$, $2005 / 06(n=3)$ and 2006/07 ( $n=3)$, with no surveys in 2003/04 and 2004/05. Each survey represented a $600 \mathrm{~km}$ flight path (approximate straight-line distance). Flights commenced at

144 dawn. Surveys were timed to coincide with periods when the maximum width of the nesting 145 beach was unaffected by tide during early morning daylight hours, hence ensuring the greatest 146 number of nesting activities could be recorded after sunrise and before the next high tide 
147 removed traces of activity. Surveys were typically split over two days to take advantage of

148 morning low sun angle, which aids detection of marine turtle nesting tracks during video

149 analysis.

150 Survey aircraft were flown at a groundspeed of 180 to $190 \mathrm{~km} \mathrm{hr}^{-1}$ at an altitude of 50 to

$15160 \mathrm{~m}$, with the aircraft positioned 100 to $200 \mathrm{~m}$ offshore. Surveys were flown in a southeast

152 direction from north to south, parallel to the coastline. The survey start location was northern

153 most limit of Pongara National Park (Fig. 1). The survey end location was the southern limit of

154 Mayumba National Park's border with the Republic of Congo. A $50 \mathrm{~km}$ section of coast to the

155 north and east of Port Gentil was excluded from all surveys as this area consisted of mangroves

156 and mudflats, which are unlikely to support leatherback turtle nesting activity.

157 A video camera was used to record footage of the nesting beach during each aerial

158 survey. Leatherback turtle nesting activities were then counted from this video data in

159 accordance with the methodology described by (Witt et al., 2009). These counts were

160 aggregated into approximate $500 \mathrm{~m}$ linear sectors of beach (data bins) that were defined by

161 waypoint data collected continuously by hand-held Global Positioning System (GPS) receivers

162 aboard the aircraft at the time of the aerial surveys. A longitude/latitude (World Geodetic

163 System (WGS) 1984 format) midpoint was determined for each of these data bins to which the

164 counts were then associated.

2.2. Satellite tracking data

Platform Transmitter Terminals (PTTs) were attached to thirty-seven adult female

leatherback turtles at nesting locations in Gabon throughout the nesting season (October to

February: 2005/06 $(n=8), 2006 / 07(n=2), 2007 / 08(n=5), 2008 / 09(n=10), 2009 / 10(n=2)$ and 2012/13 $(n=10))$. Turtles were tagged within the National Parks of Pongara $(n=18)$ and

172 Mayumba $(n=19)$; inter-nesting movements of 7 of these turtles were previously published in

173 (Witt et al., 2008) (Fig. 1, and see metadata in Supplementary Material, Table A.2.). Methods of

174 turtle capture, transmitter type and process of attachment are detailed in Witt et al. (2011). 
175 Satellite telemetry data were collected using the Argos satellite system (CLS, 2011) and

176 downloaded with the Satellite Tracking and Analysis Tool (STAT) (Coyne and Godley, 2005).

177 All locations with accuracy class $Z$ and 0 were removed (Witt et al., 2010). Data were imported

178 into the Geographical Information System (GIS) ArcMap 10.1 (ESRI, Redlands, USA

179 http://www.esri.com) and visually assessed to determine nesting events for each female. Nesting

180 events typically occurred every 9 to 11 days, the night-time location with the highest accuracy

181 location class and located on, or nearest to land within this time-frame was chosen as indicative

182 nesting event. Satellite tracking location data were then apportioned by these inter-nesting

183 periods. Five turtles departed the Gabon coast immediately after attachment of the PTT; these

184 data were not used in further analysis.

2.3. Modelling leatherback turtle distribution and relative density at sea

\subsubsection{Estimating leatherback turtle inter-nesting footprint at sea} ( $n=4), 2006 / 07(n=3), 2007 / 08(n=6), 2008 / 09(n=35), 2009 / 10(n=12)$ and $2012 / 13(n=$ 61)) we applied a speed and azimuth filter (Freitas et al., 2008; Witt et al., 2010); filtering was undertaken in R (R Development Core Team 2008; R package: argosfilter (Freitas, 2010)). Working in a projected coordinate system (Africa Albers Equal Area Conic (AAEAC)) the geometric centroid of these data was determined together with the distance of each location from the centroid; to remove spatial outliers we peeled data to the 95th quantile. The ellipsoid hull of these data was then calculated (R Development Core Team 2008; R package: cluster (Maechler et al., 2015)), this being the minimum area such that all given points lay inside, or on the boundary of the ellipsoid. An ellipsoid hull was chosen as this represents a regular geometric form which can be constructed from component metrics (i.e. semi major/minor axis, centroid and azimuth). In the presented analysis, the number of inter-nesting locations used to fit ellipsoids necessarily varied (median $n=71$ locations, inter-quartile range $n=52$ to $n=94$, 
range: $\min n=10, \max n=218)$. The length $(\mathrm{km})$ of the semi-major and semi-minor axes, the area $\left(\mathrm{km}^{2}\right)$ of the bounding ellipse, together with the shortest distance $(\mathrm{km})$ (great-circledistance: Haversine formula) of the centroid to the coast were determined. All metrics were expressed as a single value per turtle, averaging (mean) where necessary for multiple internesting periods. There was no significant difference in the median semi-major, semi-minor, or offshore distance for leatherback turtles between the nesting locations of Pongara and Mayumba National Parks (Supplementary Material, Table A.3.). We therefore calculated single countrywide median values for each ellipse metric irrespective of release location.

\subsubsection{Linking inter-nesting footprint to aerial survey data}

The average (mean) number of leatherback turtles $\mathrm{km}^{-2}$ (at sea) per nesting season was calculated using the following approach. We produced a smoothed coastline vector using a 40 $\mathrm{km}$ smoothing window. For each aerial survey dataset we used a spatial join in ArcMap to assign ellipse metrics and coastal orientation to the midpoint coordinates of the data bins (data were joined to the nearest existing location). These coordinates (projected coordinate system: AAEAC) were then transposed offshore, perpendicular to the coast, using distance of centroid to the coast (offshore distance) and coastal bearing. projected an ellipsoid polygon (major axis parallel to the coast), using grand averaged semimajor/minor axes and azimuth (coastal bearing). Each individual polygon surface was coerced to a raster of $1 \mathrm{x} 1 \mathrm{~km}$ resolution and each raster cell assigned a turtle density at sea $\left(\mathrm{km}^{-2}\right)$ which was calculated from the aerial survey data as follows. To provide for an annual estimate of the total number of nesting activities attributable to the data bin we divided the number of tracks recorded on the day of the aerial survey by the proportion of nesting activities expected for the day of the aerial survey. This proportion was determined from a normally distributed seasonal nesting curve with approximations for the beginning and end of the nesting season of 1st October to 30th April respectively (see Witt et al., (2009) for detailed analysis of leatherback 
231 turtle nesting effort in Gabon). This newly calculated annual nesting effort was then divided by

232 a clutch frequency of 6.17 ( \pm 0.47 SD (Miller 1997)), to provide the total number of turtles

233 nesting within the data bin for the season. Finally, we divided this total by the sea area of the

234 propagated ellipse to provide an at-sea density of leatherbacks turtles (turtles $\mathrm{km}^{-2}$ ) which was

235 then assigned to each raster cell. Resulting rasterised polygons were then stacked and summed

236 to provide a composite raster surface (for each aerial survey) that described an estimate of the

237 at-sea density $\left(\mathrm{km}^{-2}\right)$ of inter-nesting leatherback turtles for the nesting season.

238 These raster surfaces were then apportioned into two that reflected: (i) the peak months

239 of the Gabonese leatherback nesting season (December, January, February) and, (ii) the pre- and

240 post-peak months (October, November, and March, April) using a ratio derived from the

241 seasonal nesting curve. Where multiple aerial surveys had been flown within a nesting season

242 these surfaces were then averaged (mean); a grand average (mean) raster was then calculated

243 across all nesting seasons.

\subsection{VMS data: density mapping}

We sourced Vessel Monitoring System (VMS) data from the Government of Gabon, for

Gabon flagged trawl vessel fishing activity within the Exclusive Economic Zone (EEZ) of

Gabon for 2010, 2011 and 2012. Fisheries primarily target prawns and shrimp, sardines, tuna and a range of demersal fish species (Casale et al., 2017). The VMS data represented the best possible continuous dataset available and contained 1053923 recorded locations (2010 $(n=$ 209 033), $2011(n=452531), 2012(n=392$ 359)). All vessel identifications numbers were anonymised, as such, each VMS record consisted of a pseudo-vessel reference number, date/time stamp (UTC), geographic coordinates in decimal degrees (WGS 1984) and vessel type (by fishing gear). Data were apportioned annually; 1st October to 30th September to reflect the seasonality of leatherback turtle nesting: 2010/11 $(n=429554), 2011 / 12(n=420807)$.

For each annual VMS dataset, data were ordered by vessel reference number and 
speed calculated in knots. A speed rule was used to distinguish fishing from steaming or near-

260 stationery movement (Witt and Godley, 2007); only data with speeds $\geq 1$ or $\leq 5$ knots were

261 retained. Data were then apportioned into three seasonal groups: (i) October and November

262 (pre-peak leatherback nesting season), (ii) December to February (peak) and (iii) March and

263 April (post-peak). Seasonally grouped data were then processed as follow. For each vessel,

264 location data were then summarised (counts) to a $10 \times 10 \mathrm{~km}$ resolution raster with only the first

265 location per day per cell being counted. This raster resolution was iteratively determined to

266 provide an optimum cell size that facilitated meaningful map interpretation. This process was

267 repeated for both annual datasets and the resulting rasters averaged (mean). These seasonal

268 vessel-density rasters were then divided by the respective numbers of days of the season (i.e.

269 October - November: $\mathrm{n}=61 \mathrm{~d}$ ) to provide a surface that described the average (mean) number

270 of unique vessels day ${ }^{-1}$ within each $10 \times 10 \mathrm{~km}$ raster pixel.

271

272 2.5. AIS data: density mapping

273

274

We sourced ground and space merged Automatic Identification System (AIS) data from

ExactEarth (http://www.exactearth.com) for 2012, 2013 and 2014 for the EEZ of Gabon (space-

borne AIS data are not available prior to 2012). This dataset contained 22791353 recorded locations (2012 ( $n=3719$ 235), $2013(n=7043$ 142), $2014(n=12028$ 976)). Each record

278 consisted of Maritime Mobile Service Identity (MMSI) number, date/time stamp (UTC),

279 geographic coordinates in decimal degrees (WGS 1984) and speed (knots). Records with speed

$280=0$ knots were removed. Vessels were assigned into one of five categories: cargo $n=2240$

281 (39\%), oil (support vessels: including tankers carrying crude/refined oil and other petrochemical related products) $n=1535$ (27\%), oil (seismic research) $n=45(1 \%)$, fishing $n=106(2 \%)$ and miscellaneous (e.g. tug, passenger, recreational: $n=1150(20 \%)) ; 685(12 \%)$ vessels could not

284 be assigned to a category due to insufficient metadata. Data were apportioned annually, 1st

285 October to 30th September to reflect the seasonality of leatherback turtle nesting: 2012/13 ( $n=$ 
4637 128), 2013/14 ( $n=6327$ 527) and then divided into three seasonal groups (i) October and

November (ii) December to February and (iii) March and April.

For each seasonal dataset location data for the categories, cargo, oil (support vessels),

oil (seismic research) and fishing were treated as follows. A speed rule was used to remove locations where vessels were not 'under-way' or exhibited near-stationery movement; only data with speeds $\geq 1$ knot were retained. For each category, location data for each vessel were summarised (counts) to a $10 \times 10 \mathrm{~km}$ resolution raster with only the first location per day per cell being counted. This process was repeated for both annual datasets. Resultant rasters were averaged and seasonal vessel-density rasters calculated that described the average (mean) number of unique vessels day ${ }^{-1}$ within each $10 \times 10 \mathrm{~km}$ raster pixel.

\subsection{Calculating spatial overlap between leatherback turtles and vessel distribution} calculated as follows. Seasonal vessel density rasters (trawl and longline/purse seine fisheries, oil support, research and cargo vessels) were re-scaled to $0-1$, summed and clipped to the extent of the leatherback turtle density raster. These were then multiplied with our seasonally apportioned leatherback density rasters to provide seasonal unitless relative threat indices for: (i) the complete nesting season, (ii) the peak months (December, January, February) and (iii) the pre- and post-peak months (October, November, and March, April). To provide for data at the same spatial resolution we re-sampled our leatherback turtle at-sea density raster to the same resolution $(10 \times 10 \mathrm{~km})$ as our VMS and AIS layers using bilinear interpolation.

\section{RESULTS}


314 inter-nesting periods (Pongara $n=101$, Mayumba $n=20$ ) with an average time between nest

315 events of $10 \pm 1$ days (mean $\pm 1 \mathrm{SD}$; range $7-13$ days). Turtles primarily remained within

316 continental shelf waters (depths $\leq 200 \mathrm{~m}$ ), with $93.8 \%$ (Pongara; $n=9530$ ) and $93.1 \%$

317 (Mayumba; $n=1504$ ) of all recorded locations in these waters. Off the coast of Gabon, the

318 continental shelf break lies approximately $45 \mathrm{~km}$ from the coast to the north of the country

319 (north of Port Gentil), 50 to $60 \mathrm{~km}$ to the south of the country and within $6 \mathrm{~km}$ of the coast at

320 Port Gentil. Nintey-one percent $(n=10749)$ of all locations were located within the Exclusive

321 Economic Zone (EEZ) of Gabon (Fig. 1).

The modelled spatial pattern of inter-nesting leatherback turtles at sea indicated that the coastal waters of Pongara and Mayumba National Parks had high densities of inter-nesting leatherbacks, with a smaller hotspot offshore from Sette Cama Reserve and to the south of Port Gentil; greatest density was within and neighbouring the Mayumba Marine Park (Fig. 1).

\subsection{VMS and AIS density mapping}

\subsubsection{Fisheries} vessels across the majority of coastal waters, with peaks in density to the south of Pongara National Park, and in near-shore waters of Loango National Park. There was negligible activity off the continental shelf (Fig. 2a). Analysis of AIS fishing vessel data for longline and purse seine fisheries, in general, indicated higher density of vessels in offshore waters, approximately 100 - $200 \mathrm{~km}$ southwest of Loango National Park (Fig. 2e). There was relatively little activity on the continental shelf, with the exception of a small high-density area to the south of

338 Mayumba National Park. These distinctions in spatial patterns largely reflect the difference in gear type used by these fisheries. There was no duplication of vessels among AIS and VMS datasets. 
342 seasonal patterns for both these datasets. Mapping of VMS data indicated a north/south shift in

343 fishing activity. Maximum densities occurred in October/November near Pongara and Loango

344 National Park. Densities remained high at Loango within the months of December to April, but 345 decreased at Pongara (Fig. 2b,c,d). Mapping of AIS data indicated that October/November were 346 peak months for longline and purse seine fisheries with maximum densities occurring southwest 347 of Loango National Park. There was an indication of increased fisheries activity immediately to 348 the south of Mayumba Marine Park during October to February (Fig. 2f,g,h).

\subsubsection{Oil industry and cargo vessels}

Mapping of AIS data (October to April) revealed marked differences between vessel categories. For example, oil support vessels formed defined routes between the ports of Libreville and Port Gentil, as well as westward from Port Gentil (Fig. 3a). Mapping the distribution of cargo vessels (i.e. bulk carriers, container vessels) identified two routes. The first lay parallel to the coast from Port Gentil in the north to the Gabon/Congo EEZ border in the south and broadly mirrored the $200 \mathrm{~m}$ isobath, the second ran westward from the port of Libreville (Fig. 3i). There was no marked differences among seasonal density mapping for oil support vessels, or for cargo vessels (Fig. 3b,c,d,j,k,l). Hotspots of seismic vessel movement occurred in continental shelf waters, and were primarily concentrated to the south of Port Gentil and in coastal waters of Loango National Park and Sette Cama Reserve (Fig. 3e). There were clear differences among seasonal density mapping for seismic vessels. There was relatively high seismic vessel presence to the southwest of Mayumba Marine Park at the beginning of the nesting season (October/November), to the south of Port Gentil during peak season (December to February) and in coastal waters of Loango National Park in March/April (Fig. 3f,g,h). These seasonal differences may reflect seasonal legislative restrictions or indicate interest in exploitation. However, it should be noted that presence of seismic vessels does not necessarily indicate vessels were engaged in seismic survey activity. 


\subsection{Spatial overlap between leatherback turtles and vessel distribution} coastal waters of Pongara and Mayumba National Park were subject to high levels of putative threat throughout the leatherback nesting season (Fig. 4b). There were also isolated areas of moderate/high putative threat within coastal waters from Port Gentil to Sette Cama Reserve, primarily due to coastal fisheries and seismic vessels present within the area. There was variation in magnitude and timing of threat among locations. Spatially, co-occurrence was greatest at Pongara at the beginning of the season (October/November) (Fig. 4d), principally due to the heightened level of coastal fisheries activity, and from Port Gentil to Sette Cama and within and adjacent to Mayumba Marine Park during peak season (December/January/February) and post-peak (March/April) (Fig. 4f,h).

\section{DISCUSSION} used method to determine densities of animals at sea, relying on data being collected either by way of boat or aerial transect (Aerts et al., 2013; Hammond et al., 2002). Whilst distancesampling is well established and relatively accessible it has some limitations (Evans and Hammond, 2004). The presented analysis sought to develop a complementary methodology to estimate at-sea distributions and relative densities that was independent of the need to sight species at sea, and that in turn could be applied to other species of sea turtles for cumulative assessments. With adaptation, this methodology may also have utility in defining critical habitats for other central-place foragers such as pinnipeds, or sea bird species (Cronin et al.,

394 2013; Grecian et al., 2010; Sharples et al., 2012). at its greatest within the marine environment (Halpern et al., 2008), but may not take into 
account distribution and densities of species within these areas. Furthermore, it is possible that

398 areas subject to relatively high cumulative threat, and with high species densities, will fail to

399 attract adequate conservation effort (Lewison et al., 2014). Identifying key areas where species

400 aggregate may facilitate the decision process of where and when to best place conservation

401 resources to achieve maximum benefit (Hart et al., 2012). With this analysis, we sought to

402 further the process of impact assessment by formulating a cumulative threat index that assessed

403 multiple threats from vessels, whilst at the same time integrating modelled distribution and

404 densities of a species of conservation concern. Our analysis does not attempt to differentiate

405 threats from vessels by magnitude, or relative importance. Whilst the presented analysis is

406 primarily spatial in nature, we also sought to present these spatial patterns in relation to the peak

407 and pre- and post-peak months of the leatherback nesting season. However, threat to turtles and

408 subsequent impacts will also be related to other compounding factors such as turtle behaviour

409 (diving or at surface) and temporal influences such as seasonal fisheries activity (deployment of

410 season-specific gear types) or oil industry activity/spills. It remains likely that many 'threats'

411 require further knowledge or assessment to quantify probable impacts. To do so effectively,

412 species sensitivity to threats needs to be assessed, this in turn, would additionally allow

413 assignment of weights for calculating cumulative impact.

414 Our analysis revealed that within the peak leatherback nesting season (December to

415 February), when approximately $80 \%$ of the season's nesting takes place (Witt et al., 2009),

416 greatest densities of leatherback turtles likely occur in coastal waters adjacent to Pongara and

417 Mayumba National Parks, with a smaller 'hotspot' to the west of Sette Cama Reserve.

418 Contextualising these at-sea density and distribution patterns, with vessel movements derived

419 from VMS and AIS location data, suggests that vessels associated with various industries have

420 the potential to interact with inter-nesting leatherback turtles within Gabonese coastal waters,

421 throughout the nesting season.

422 Density mapping of the Gabon trawl fisheries fleet (for which VMS data were

423 available) indicated that this fleet could interact with at-sea leatherbacks at all high-density

424 leatherback areas. In coastal waters adjacent to Pongara National Park, the potential for this was 
greatest at the start of the nesting season. There was a subsequent southerly shift in vessel densities for coastal fisheries later in the nesting leatherback season. Analysis of AIS fisheries data, which predominantly comprised of large Distant Water Fleet (DWF) vessels, suggested that there was no activity for this category of vessel within coastal waters of Pongara National Park. There was however, a hotspot of DWF vessel activity just within, and adjoining the

430 southwest/south-easterly border of Mayumba Marine Park at the start of, and during peak nesting season. The coastal waters of Pongara National Park had the highest density of vessels associated with shipping routes for both oil industry and cargo vessels. There were notable hotspots of vessel movements both between the ports of Libreville and Port Gentil in coastal waters, and offshore from these ports to the open ocean, throughout the nesting season. Seismic vessel activity was primarily confined to the coastal waters south of Port Gentil and to the southwest of Mayumba Marine Park. The coastal waters of Pongara National Park had high levels of cumulative threat throughout the nesting season. Cumulative threat mapping indicated the coastal waters from south of Port Gentil to Mayumba National Park had greatest levels of cumulative threat through the peak and post-peak nesting season. approach only uses data sourced from adult females and therefore does not consider juvenile or male turtle habitat use. The distribution and density estimates of female leatherback nesting activity were derived from aerial survey data sourced from seven aerial surveys (2002/03 to 2006/07). Inclusion of additional aerial survey data within this analysis may modify model outputs; although unpublished data (Formia pers. comm.) suggests nesting patterns are similar. Our method does not account for any temporal variability in nesting season that may be present between the north and south of the country (Witt et al., 2009). This would be unlikely to affect the modelled at-sea densities of leatherbacks, but should be considered when interpreting threat mapping. Similarly, our method utilises a normally distributed nesting curve to calculate annual estimates of the total number of nesting activities for each data bin, with approximations for the

451 beginning and end of the nesting season of 1st October to 30th April respectively. These 
number of turtles nesting within each data bin for the season we applied a clutch frequency of

4546.17 (Miller 1997). As our main goal was to demonstrate overlap of turtle distribution and

455 density with vessel activity using a relative threat index the value for clutch frequency was not

456 critical. However, it should be noted that clutch frequency is a critical metric in determining

457 population abundance (Esteban et al., 2017).

458 It is also probable that our vessel densities represent underestimations. Our analysis

459 only considers vessels that are legally required to transmit their locations by way of VMS or

460 AIS. Similarly, these systems need to be enabled and transmitting. Applying a slow speed filter

461 to all AIS data to remove vessel traffic that was not 'under-way' may have the effect of

462 removing some locations for vessels deploying purse seine gear; although, it is highly unlikely

463 that a vessel will remain motionless 'at sea' given the influence of wind and or tide and currents.

464 For coastal fisheries, we only evaluate data for the Gabon fleet. Vessel movements for DWFs

465 and artisanal fisheries are not considered; therefore, these sectors remain un-assessed. In

466 addition, our VMS data are sourced prior to September 2012. Subsequent changes to fisheries

467 management regimes within Gabon, including the definition of no-take and exclusion zones, are

468 likely to have modified vessel movement patterns in the vicinity of these zones. Finally, whilst

469 some of our component data layers do not overlap temporally, primarily due to logistical or

470 financial constraints, they represent the best available data from which to formulate this

471 analysis. Notwithstanding these temporal inconsistencies, we consider that the methodology

472 presented is sound and capable of generating realistic density estimates. However, we

473 acknowledge that these density estimates and associated threat indices may be improved with

474 temporally concurrent data.

475 Although the presented analysis focuses on a single species, much of the associated

476 threats will apply to other air-breathing mobile marine vertebrates in Gabonese coastal waters.

477 These species include olive ridley sea turtles (Maxwell et al., 2011; Metcalfe et al., 2015),

478 humpback dolphins (Sousa teuszii) (Collins, 2015; Weir and Collins, 2015) and humpback

479 whales (Megaptera novaeangliae) (Rosenbaum et al., 2014); although mitigation and

480 management measures would undoubtedly be species specific. Such an approach to monitoring 
key activities of relevance to conservation is considered among the key global priorities for cetacean research (Parsons et al 2015). This is especially salient given the emerging evidence that some baleen whales have limited potential for vessel avoidance (McKenna et al 2015).

EEZ: confined to a $15 \times 60 \mathrm{~km}$ strip of coastal waters to the far south of the Gabonese EEZ.

486 Typically, small protected areas offer limited conservation benefits (Gaines et al., 2010)

487 particularly to mobile species. A recent comprehensive marine spatial planning review has been made of Gabon's territorial waters which integrated data from this analysis. This review has led to, approximately $23 \%$ of Gabon's territorial waters and EEZ being designated as MPAs, in which commercial fishing will be excluded. For leatherback turtles, this is likely to result in increased protection of inter-nesting at-sea habitat in waters adjacent to Mayumba National Park, in near-shore waters to the south of Port Gentil and to the north, at Pongara (Fig. 5). Indeed, associated management strategies protecting marine habitats and improving fisheries management, including improved surveillance and enforcement of fisheries, as well as designation of exclusion zones around maritime oil and gas infrastructure, likely already influence some vessel movements in key areas identified in this study. Ultimately, with increased spatio-temporal understanding of threat (gleaned from continued collection and analysis of vessel movements) and species/vessel interactions (collected by way of boat observer programs and post-mortems), together with better temporal understanding of impacts (e.g. deployment of season-specific gear types), MPA design and management strategies may be tailored and fine-tuned to deliver a holistic network of protected areas that provide protection for a suit of Gabon's biodiversity rich marine species.

\section{ACKNOWLEDGEMENTS}

We thank the following for support and funding: CARPE (Central African Regional Program for the Environment, Darwin Initiative, EAZA ShellShock Campaign, Gabon Sea Turtle Partnership with funding from the Marine Turtle Conservation Fund (United States Fish 
509 and Wildlife Service, U.S. Department of the Interior), Harvest Energy, Large Pelagics

510 Research Centre at the University of Massachusetts (Boston), NERC, Vaalco Energy and the

511 Wildlife Conservation Society. We are sincerely grateful to the field teams and logistics staff

512 who assisted in the aerial and ground surveys and with field-site assistance. BJG and MJW

513 receive funding from the Natural Environment Research Council (NE/J012319/1), the European

514 Union and the Darwin Initiative. The authors would like to acknowledge the constructive input

515 from three anonymous referees, the Editor and the Associate Editor. 
Aarts, G., MacKenzie, M., McConnell, B., Fedak, M., Matthiopoulos, J., 2008. Estimating 160.

Aerts, L.A.M., McFarland, A.E., Watts, B.H., Lomac-MacNair, K.S., Seiser, P.E., Wisdom, S.S., Kirk, A.V., Schudel, C.A., 2013. Marine mammal distribution and abundance in an offshore sub-region of the northeastern Chukchi Sea during the open-water season. Cont. Shelf Res. 67, 116-126. doi:10.1016/j.csr.2013.04.020

Alfaro-Shigueto, J., Dutton, P.H., Van Bressem, M., Mangel, J., 2007. Interactions between leatherback turtles and Peruvian artisanal fisheries. Chelonian Conserv. Biol. 6, 129-134.

Becker, E.A., Forney, K.A., Foley, D.G., Smith, R.C., Moore, T.J., Barlow, J., 2014. Predicting seasonal density patterns of California cetaceans based on habitat models. Endanger. Species Res. 23, 1-22.

Briscoe, D.K., Maxwell, S.M., Kudela, R., Crowder, L.B., Croll, D., 2016. Are we missing important areas in pelagic marine conservation? Redefining conservation hotspots in the ocean. Endanger. Species Res. 29, 229-237.

Buckland, S.T., Anderson, D.R., Burnham, K.P., Laake, J.L., Borchers, D., Thomas, L., 2001. Introduction to distance sampling estimating abundance of biological populations. Oxford University Press, Oxford.

CLS, 2011. Argos user's manual. http://www.argossystem.org/documents/userarea/argos_manual_en.pdf.

Casale, P., Abitsi, G., Aboro, M.P., Agamboue, P.D., Agbode, L., Allela, N.L., Angueko, D., Nguema, J.N.B.B., Boussamba, F., Cardiec, F., 2017. A first estimate of sea turtle bycatch in the industrial trawling fishery of Gabon. Biodivers. Conserv. 1-13.

Collins, T., 2015. Chapter Three-Re-assessment of the Conservation Status of the Atlantic Humpback Dolphin, Sousa teuszii (), Using the IUCN Red List Criteria. Adv. Mar. Biol. 72, 47-77.

Coyne, M.S., Godley, B.J., 2005. Satellite Tracking and Analysis Tool (STAT): an integrated system for archiving, analyzing and mapping animal tracking data. Mar. Ecol. Prog. Ser. 301, 1-7.

Cronin, M., Pomeroy, P., Jessopp, M., 2013. Size and seasonal influences on the foraging range of female grey seals in the northeast Atlantic. Mar. Biol. 160, 531-539.

Billes, A., Fretey, J., Mourndembe, J., 2003. Monitoring of leatherback turtles in Gabon. Presented at the Proceedings of the 22nd Annual Symposium of Sea Turtle Biology and Conservation, pp. 131-132.

Denkinger, J., Parra, M., Muñoz, J.P., Carrasco, C., Murillo, J.C., Espinosa, E., Rubianes, F., Koch, V., 2013. Are boat strikes a threat to sea turtles in the Galapagos Marine Reserve? Ocean Coast. Manag. 80, 29-35. doi:10.1016/j.ocecoaman.2013.03.005

Edrén, S., Wisz, M.S., Teilmann, J., Dietz, R., Söderkvist, J., 2010. Modelling spatial patterns in harbour porpoise satellite telemetry data using maximum entropy. Ecography 33, 698-708.

Esteban, N., Mortimer, J.A., Hays, G.C., 2017. How numbers of nesting sea turtles can be overestimated by nearly a factor of two. Presented at the Proc. R. Soc. B, The Royal Society, p. 20162581.

Evans, P.G., Hammond, P.S., 2004. Monitoring cetaceans in European waters. Mammal Rev. 34, 131-156.

Follett, L., Genschel, U., Hofmann, H., 2014. A graphical exploration of the Deepwater Horizon oil spill. Comput. Stat. 29, 121-132.

Forney, K.A., Becker, E.A., Foley, D.G., Barlow, J., Oleson, E.M., 2015. Habitat-based models of cetacean density and distribution in the central North Pacific. Endanger. Species Res. 27, 1-20. 
Fossette, S., Witt, M., Miller, P., Nalovic, M., Albareda, D., Almeida, A., Broderick, A., Chacón-Chaverri, D., Coyne, M., Domingo, A., 2014. Pan-Atlantic analysis of the overlap of a highly migratory species, the leatherback turtle, with pelagic longline fisheries. Proc. R. Soc. B Biol. Sci. 281. doi:DOI: 10.1098/rspb.2013.3065

Freitas, C., 2010. argosfilter: Argos locations filter. R package version 0.62.

Freitas, C., Lydersen, C., Fedak, M.A., Kovacs, K.M., 2008. A simple new algorithm to filter marine mammal Argos locations. Mar. Mammal Sci. 24, 315-325.

Gaines, S.D., White, C., Carr, M.H., Palumbi, S.R., 2010. Designing marine reserve networks for both conservation and fisheries management. Proc. Natl. Acad. Sci. 107, 18286-18293. doi:10.1073/pnas.0906473107

Grecian, W.J., Inger, R., Attrill, M.J., Bearhop, S., Godley, B.J., Witt, M.J., Votier, S.C., 2010. Potential impacts of wave- powered marine renewable energy installations on marine birds. Ibis 152, 683-697.

Halpern, B.S., Walbridge, S., Selkoe, K.A., Kappel, C.V., Micheli, F., D’Agrosa, C., Bruno, J.F., Casey, K.S., Ebert, C., Fox, H.E., Fujita, R., Heinemann, D., Lenihan, H.S., Madin, E.M.P., Perry, M.T., Selig, E.R., Spalding, M., Steneck, R., Watson, R., 2008. A Global Map of Human Impact on Marine Ecosystems. Science 319, 948 952.

Hammond, P., Berggren, P., Benke, H., Borchers, D., Collet, A., Heide- Jørgensen, M., Heimlich, S., Hiby, A., Leopold, M.F., Øien, N., 2002. Abundance of harbour porpoise and other cetaceans in the North Sea and adjacent waters. J. Appl. Ecol. 39, 361-376.

Hart, K.M., Lamont, M.M., Fujisaki, I., Tucker, A.D., Carthy, R.R., 2012. Common coastal foraging areas for loggerheads in the Gulf of Mexico: Opportunities for marine conservation. Biol. Conserv. 145, 185-194.

Hintzen, N.T., Bastardie, F., Beare, D., Piet, G.J., Ulrich, C., Deporte, N., Egekvist, J., Degel, H., 2012. VMStools: open-source software for the processing, analysis and visualisation of fisheries logbook and VMS data. Fish. Res. 115, 31-43.

Hitipeuw, C., Dutton, P.H., Benson, S., Thebu, J., Bakarbessy, J., 2007. Population Status and Internesting Movement of Leatherback Turtles, Dermochelys coriacea, Nesting on the Northwest Coast of Papua, Indonesia. Chelonian Conserv. Biol. 6, 28-36. doi:10.2744/1071-8443(2007)6[28:PSAIMO]2.0.CO;2

Huang, H.-W., 2015. Conservation Hotspots for the Turtles on the High Seas of the Atlantic Ocean. PloS One 10, e0133614.

Hyrenbach, K.D., Forney, K.A., Dayton, P.K., 2000. Marine protected areas and ocean basin management. Aquat. Conserv. Mar. Freshw. Ecosyst. 10, 437-458. doi:10.1002/1099-0755(200011/12)10:6<437::AID-AQC425>3.0.CO;2-Q

Lauriano, G., Panigada, S., Casale, P., Pierantonio, N., Donovan, G., 2011. Aerial survey abundance estimates of the loggerhead sea turtle Caretta caretta in the Pelagos Sanctuary, northwestern Mediterranean Sea. Mar Ecol Prog Ser 437, 291-302.

Lewison, R.L., Crowder, L.B., Wallace, B.P., Moore, J.E., Cox, T., Zydelis, R., McDonald, S., DiMatteo, A., Dunn, D.C., Kot, C.Y., 2014. Global patterns of marine mammal, seabird, and sea turtle bycatch reveal taxa-specific and cumulative megafauna hotspots. Proc. Natl. Acad. Sci. 111, 5271-5276.

Lewison, R.L., Freeman, S.A., Crowder, L.B., 2004. Quantifying the effects of fisheries on threatened species: the impact of pelagic longlines on loggerhead and leatherback sea turtles. Ecol. Lett. 7, 221-231.

Lum, L.L., 2006. Assessment of incidental sea turtle catch in the artisanal gillnet fishery in Trinidad and Tobago, West Indies. Appl. Herpetol. 3, 357-368.

Maechler, M., Rousseeuw, P., Struyf, A., Hubert, M., Hornik, K., 2015. cluster: Cluster Analysis Basics and Extensions. R package version 1.15.2. 
Matthiopoulos, J., McConnell, B., Duck, C., Fedak, M., 2004. Using satellite telemetry and aerial counts to estimate space use by grey seals around the British Isles. J. Appl. Ecol. 41, 476-491.

Maxwell, S.M., Ban, N.C., Morgan, L.E., 2014. Pragmatic approaches for effective management of pelagic marine protected areas. Endanger. Species Res. 26, 59-74.

Maxwell, S.M., Breed, G.A., Nickel, B.A., Makanga-Bahouna, J., Pemo-Makaya, E., Parnell, R.J., Formia, A., Ngouessono, S., Godley, B.J., Costa, D.P., Witt, M.J., Coyne, M.S., 2011. Using satellite tracking to optimize protection of long-lived marine species: olive ridley sea turtle conservation in central Africa. PloS One 6, e19905.

Metcalfe, K., Agamboué, P.D., Augowet, E., Boussamba, F., Cardiec, F., Fay, J.M., Formia, A., Kema, J.R.K., Kouerey, C., Mabert, B.D.K., 2015. Going the extra mile: Ground-based monitoring of olive ridley turtles reveals Gabon hosts the largest rookery in the Atlantic. Biol. Conserv. 190, 14-22.

Miller, J.D., 1997. Reproduction in sea turtles. In: Lutz, P.L., Musick, J.A. (Eds.), The Biology of Sea Turtles. CRC Press, Boca Raton, p. 432.

Nabavi, S.M.B., Zare, R., Vaghefi, M.E., 2012. Nesting Activity and Conservation Status of the Hawksbill Turtle(Eretmochelys imbricata) in Persian Gulf. J. Life Sci. 6, 74-79.

Natale, F., Gibin, M., Alessandrini, A., Vespe, M., Paulrud, A., 2015. Mapping Fishing Effort through AIS Data. PloS One 10, e0130746.

Nel, R., Punt, A.E., Hughes, G.R., 2013. Are coastal protected areas always effective in achieving population recovery for nesting sea turtles? PloS One 8, e63525.

Nelms, S.E., Piniak, W.E., Weir, C.R., Godley, B.J., 2016. Seismic surveys and marine turtles: An underestimated global threat? Biol. Conserv. 193, 49-65.

Pikesley, S.K., Agamboue, P.D., Bonguno, E.A., Boussamba, F., Cardiec, F., Fay, J.M., Formia, A., Godley, B.J., Laurance, W.F., Mabert, B.D.K., others, 2013. Here today, here tomorrow: Beached timber in Gabon, a persistent threat to nesting sea turtles. Biol. Conserv. 162, 127-132.

Pikesley, S.K., Broderick, A.C., Cejudo, D., Coyne, M.S., Godfrey, M.H., Godley, B.J., Lopez, P., López-Jurado, L.F., Elsy Merino, S., Varo-Cruz, N., Witt, M.J., Hawkes, L.A., 2014. Modelling the niche for a marine vertebrate: a case study incorporating behavioural plasticity, proximate threats and climate change. Ecography 38, 803812. doi:10.1111/ecog.01245

Roe, J.H., Morreale, S.J., Paladino, F.V., Shillinger, G.L., Benson, S.R., Eckert, S.A., Bailey, H., Tomillo, P.S., Bograd, S.J., Eguchi, T., 2014. Predicting bycatch hotspots for endangered leatherback turtles on longlines in the Pacific Ocean. Proc. R. Soc. B Biol. Sci. 281, 20132559.

Rosenbaum, H.C., Maxwell, S.M., Kershaw, F., Mate, B., 2014. Long- Range Movement of Humpback Whales and Their Overlap with Anthropogenic Activity in the South Atlantic Ocean. Conserv. Biol. 28, 604-615.

Scheidat, M., Verdaat, H., Aarts, G., 2012. Using aerial surveys to estimate density and distribution of harbour porpoises in Dutch waters. J. Sea Res. 69, 1-7.

Seminoff, J.A., Eguchi, T., Carretta, J., Allen, C.D., Prosperi, D., Rangel, R., Gilpatrick Jr, J.W., Forney, K., Peckham, S.H., 2014. Loggerhead sea turtle abundance at a foraging hotspot in the eastern Pacific Ocean: implications for at-sea conservation. Endanger. Species Res. 24, 207-220.

Sharples, R.J., Moss, S.E., Patterson, T.A., Hammond, P.S., 2012. Spatial variation in foraging behaviour of a marine top predator (Phoca vitulina) determined by a largescale satellite tagging program. PLoS One 7, e37216.

Shelmerdine, R.L., 2015. Teasing out the detail: how our understanding of marine AIS data can better inform industries, developments, and planning. Mar. Policy 54, 17-25. 
Stapleton, S., Peacock, E., Garshelis, D., 2015. Aerial surveys suggest long- term stability in the seasonally ice- free Foxe Basin (Nunavut) polar bear population. Mar. Mammal Sci.

Thomas, L., Buckland, S.T., Rexstad, E.A., Laake, J.L., Strindberg, S., Hedley, S.L., Bishop, J.R., Marques, T.A., Burnham, K.P., 2010. Distance software: design and analysis of distance sampling surveys for estimating population size. J. Appl. Ecol. 47, 5-14.

Tiwari, M., Wallace, B.P. \& Girondot, M. 2013. Dermochelys coriacea (Southeast Atlantic Ocean subpopulation). The IUCN Red List of Threatened Species 2013.

Vermard, Y., Rivot, E., Mahévas, S., Marchal, P., Gascuel, D., 2010. Identifying fishing trip behaviour and estimating fishing effort from VMS data using Bayesian Hidden Markov Models. Ecol. Model. 221, 1757-1769.

Wedding, L., Maxwell, S., Hyrenbach, D., Dunn, D., Roberts, J., Briscoe, D., Hines, E., Halpin, P., 2016. Geospatial approaches to support pelagic conservation planning and adaptive management. Endanger. Species Res. 30, 1-9.

Weir, C.R., Collins, T., 2015. Chapter Four-A Review of the Geographical Distribution and Habitat of the Atlantic Humpback Dolphin (Sousa teuszii). Adv. Mar. Biol. 72, 79117.

Whittock, P.A., Pendoley, K.L., Hamann, M., 2014. Inter-nesting distribution of flatback turtles Natator depressus and industrial development in Western Australia. Endanger. Species Res. 26, 25-38.

Witt, M.J., Akesson, S., Broderick, A.C., Coyne, M.S., Ellick, J., Formia, A., Hays, G.C., Luschi, P., Stroud, S., Godley, B.J., 2010. Assessing accuracy and utility of satellite-tracking data using Argos-linked Fastloc-GPS. Anim. Behav. 80, 571-581.

Witt, M.J., Baert, B., Broderick, A.C., Formia, A., Fretey, J., Gibudi, A., Mounguengui, G.A.M., Moussounda, C., Ngouessono, S., Parnell, R.J., 2009. Aerial surveying of the world's largest leatherback turtle rookery: a more effective methodology for large-scale monitoring. Biol. Conserv. 142, 1719-1727.

Witt, M.J., Bonguno, E.A., Broderick, A.C., Coyne, M.S., Formia, A., Gibudi, A., Mounguengui, G.A.M., Moussounda, C., NSafou, M., Nougessono, S., 2011. Tracking leatherback turtles from the world's largest rookery: assessing threats across the South Atlantic. Proc. R. Soc. B Biol. Sci. 278, 2338-2347.

Witt, M.J., Broderick, A.C., Coyne, M.S., Formia, A., Ngouessono, S., Parnell, R.J., Sounguet, G.-P., Godley, B.J., 2008. Satellite tracking highlights difficulties in the design of effective protected areas for Critically Endangered leatherback turtles Dermochelys coriacea during the inter-nesting period. Oryx 42, 296-300.

Witt, M.J., Godley, B.J., 2007. A Step Towards Seascape Scale Conservation: Using Vessel Monitoring Systems (VMS) to Map Fishing Activity. PloS One 2, e1111. 
712 Fig. 1. Location data (black circles) of satellite tracked inter-nesting leatherback turtles tracked

713 from, (a) Pongara National Park $(n=18)$ and (b) Mayumba National Park $(n=14)$. Tagging

714 locations (white stars). (c) Modelled leatherback turtle density at-sea October-April. Densities

715 (turtles $100 \mathrm{~km}^{-2}$ apportioned by percentiles) are drawn in accordance with the figure legend.

$716200 \mathrm{~m}$ continental shelf isobath (broken line) and EEZ maritime boundaries (broken line

717 polygon). In part (c) coastal National Parks (dark-grey polygons) and reserves (mid-grey

718 polygons) and the ports of Libreville and Port Gentil are labelled. Mayumba National Park

719 (Marine Protected Area (MPA)), broken white polygon. Part (c) is located according to the

720 inset. All parts drawn to differing spatial scales. Map drawn to Projected Coordinate System:

721 Africa Albers Equal Area Conic.

722

723 Fig. 2. Density mapping of fisheries activity derived from Vessel Monitoring System (VMS)

724 and Automatic Identification System (AIS) data. (a-d) VMS data for leatherback nesting

725 seasons 2010/11 and 2011/12. A speed rule was applied to distinguish fishing from steaming or

726 near-stationery movement (Witt \& Godley 2007); only data with speeds $\geq 1$ or $\leq 5$ knots were

727 retained. (e-h) AIS data for leatherback nesting seasons 2012/13 and 2013/14. A speed rule was

728 applied to remove near-stationery movement; only data with speeds $\geq 1$ knot were retained. For

729 each dataset, data for the complete nesting season (a,e) were apportioned into three seasonal

730 groups: (b,f) October and November, $(\mathrm{c}, \mathrm{g})$ December to February and $(\mathrm{d}, \mathrm{h})$ March and April.

731 Location data were summarised (counts) to a $10 \times 10 \mathrm{~km}$ resolution raster with only the first

732 location per day per cell being counted. Annual averaged seasonal density rasters were then

733 divided by the respective numbers of days of the season. This provided a surface that described

734 the average (mean) number of unique vessels day ${ }^{-1}$ within each $10 \times 10 \mathrm{~km}$ raster pixel. Parts

735 (a,b,c,d) and (e,f,g,h) are drawn to differing spatial scales. All other map features are drawn and

736 labelled in accordance with Fig. 1. Map drawn to Projected Coordinate System: Africa Albers

737 Equal Area Conic.

738 
Fig. 3. Density mapping of vessel activity categorised as, (a-d) oil support vessels, including tankers carrying crude/refined oil and other petrochemical related products, (e-h) seismic research vessels and (i-1) cargo vessels, derived from Automatic Identification System (AIS) data for leatherback nesting seasons 2012/13 and 2013/14. A speed rule was applied to remove near-stationery movement; only data with speeds $\geq 1$ knot were retained. Data for the complete nesting season $(\mathrm{a}, \mathrm{e}, \mathrm{i})$ were then apportioned into three seasonal groups: $(\mathrm{b}, \mathrm{f}, \mathrm{j})$ October and November, $(c, g, k)$ December to February and $(d, h, i)$ March and April. Location data were summarised (counts) to a $10 \times 10 \mathrm{~km}$ resolution raster with only the first location per day per cell being counted. Annual averaged seasonal density rasters were then divided by the respective numbers of days of the season. This provided a surface that described the average (mean) number of unique vessels day ${ }^{-1}$ within each $10 \times 10 \mathrm{~km}$ raster pixel. All parts drawn to the same spatial scale. All other map features are drawn and labelled in accordance with Fig. 1. Map drawn to Projected Coordinate System: Africa Albers Equal Area Conic.

Fig. 4. Cumulative seasonal vessel densities (a,c,e,g). Vessel density rasters were re-scaled 0-1 and summed. Threat index for inter-nesting leatherback turtles (b,d,f,h). Cumulative vessel density rasters were multiplied by leatherback density rasters. To provide for data at the same spatial resolution leatherback turtle at-sea density raster were re-sampled to the same resolution $(10 \times 10 \mathrm{~km})$ as the VMS and AIS layers using bilinear interpolation. Data for the complete nesting season $(\mathrm{a}, \mathrm{b})$ were then apportioned into three seasonal groups: $(\mathrm{c}, \mathrm{d})$ October and November, (e,f) December to February and (g,h) March and April. All parts drawn to the same spatial scale. All other map features are drawn and labelled in accordance with Fig. 1. Map drawn to Projected Coordinate System: Africa Albers Equal Area Conic.

Fig. 5. Leatherback turtle density at-sea and Marine Protected Areas. Leatherback turtle

764 densities (turtles $100 \mathrm{~km}^{-2}$ apportioned by percentiles: October-April) are drawn in accordance 765 with the figure legend. Mayumba National Park (Marine Protected Area (MPA)), broken white polygon, all other MPAs, black hatched polygons. All other map features are drawn and labelled 
767 in accordance with Fig. 1. Map drawn to Projected Coordinate System: Africa Albers Equal 768 Area Conic.

769 
771 Fig. 1.

772

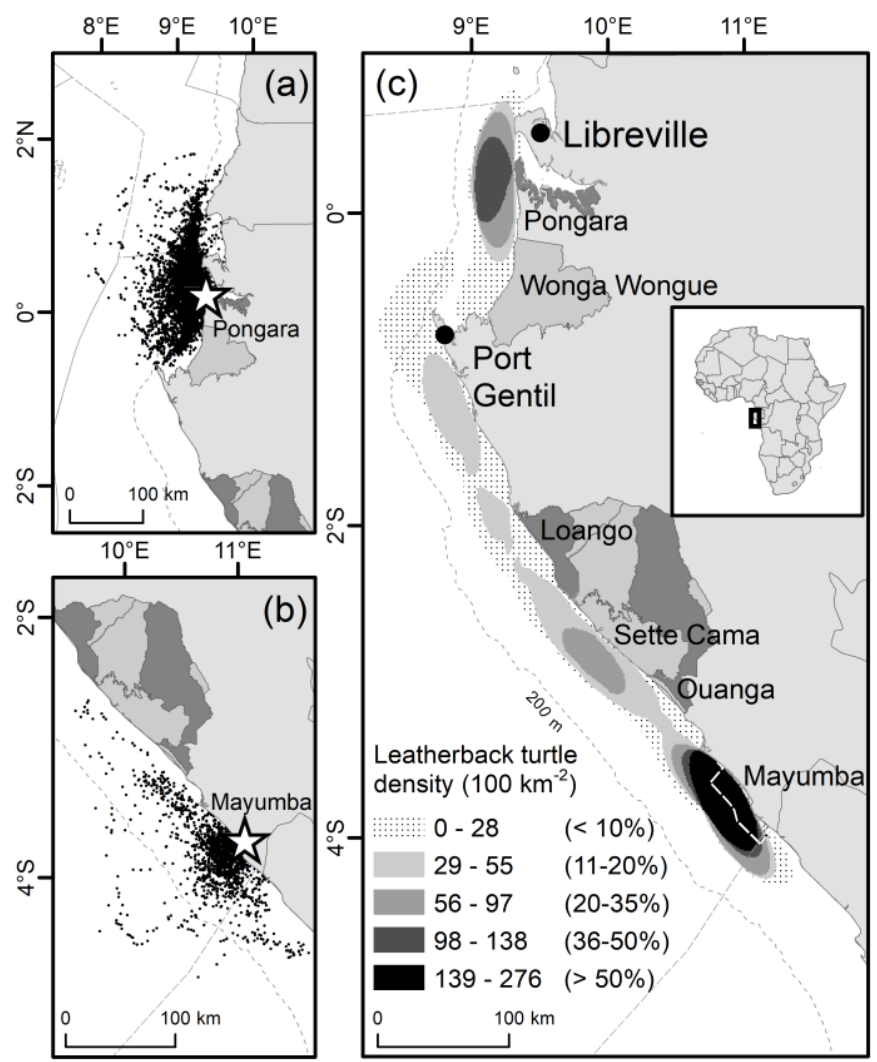

773

774 
Fig. 2.

776
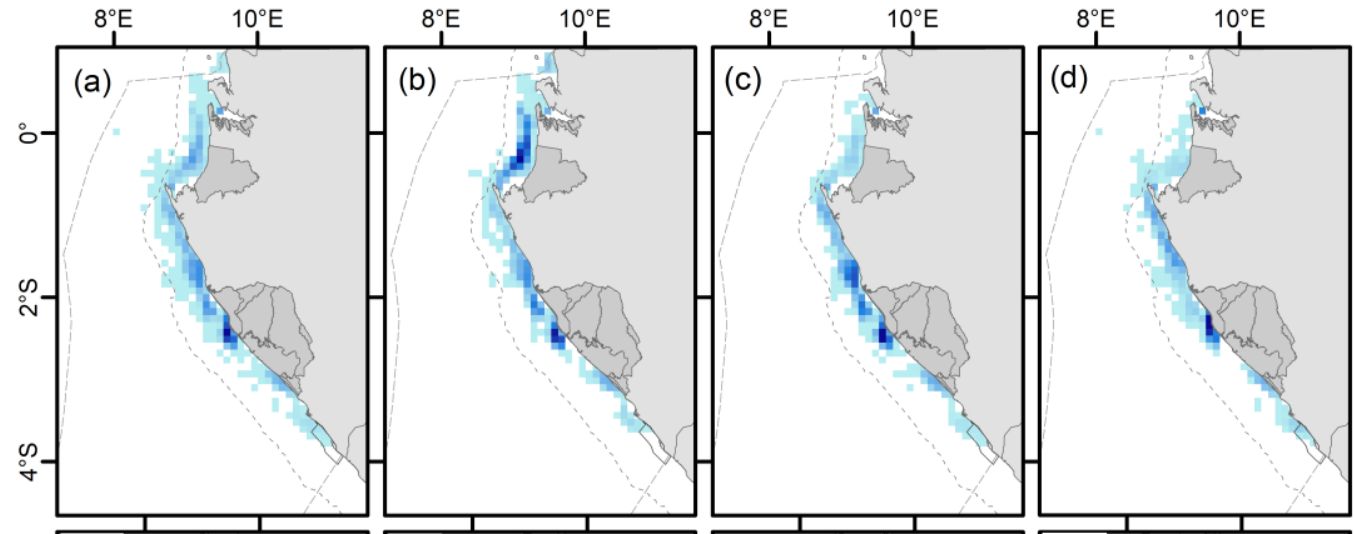

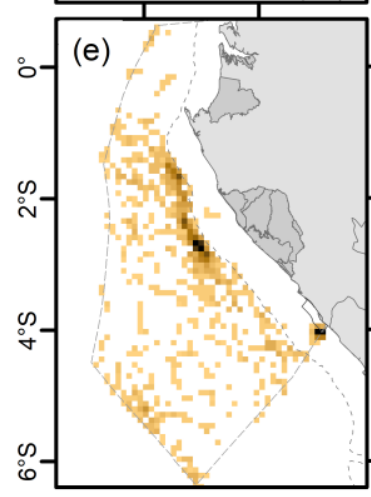

All season

Trawl

fisheries

vessels day ${ }^{-1}$

(a)

(n: mean)

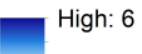

Low: $<0.1$

Longline and purse seine

fisheries

(e)

vessels day

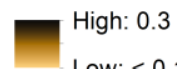
(n: mean)

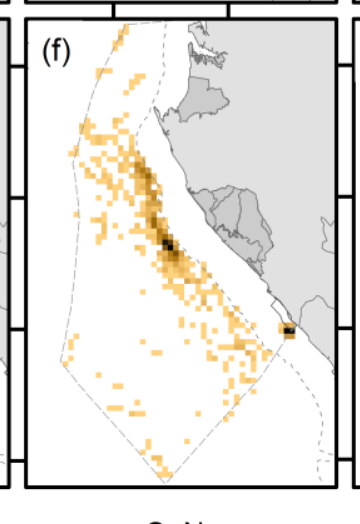

777

(g)

(b)

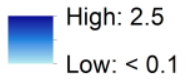

(f)

High: 0.25

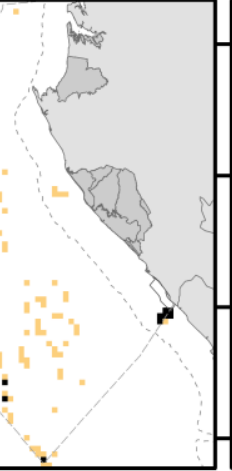

D, J, F

(c)

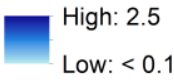

(g)

High: 0.25

Low: $<0.01$ (h)
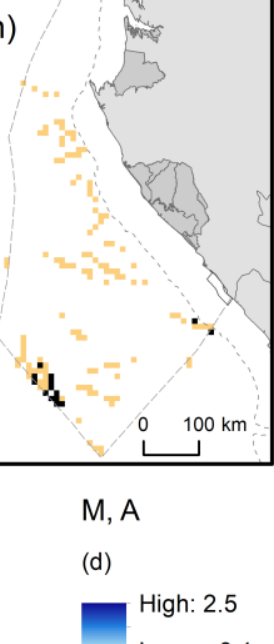

(h)

High: 0.25 
Fig. 3.
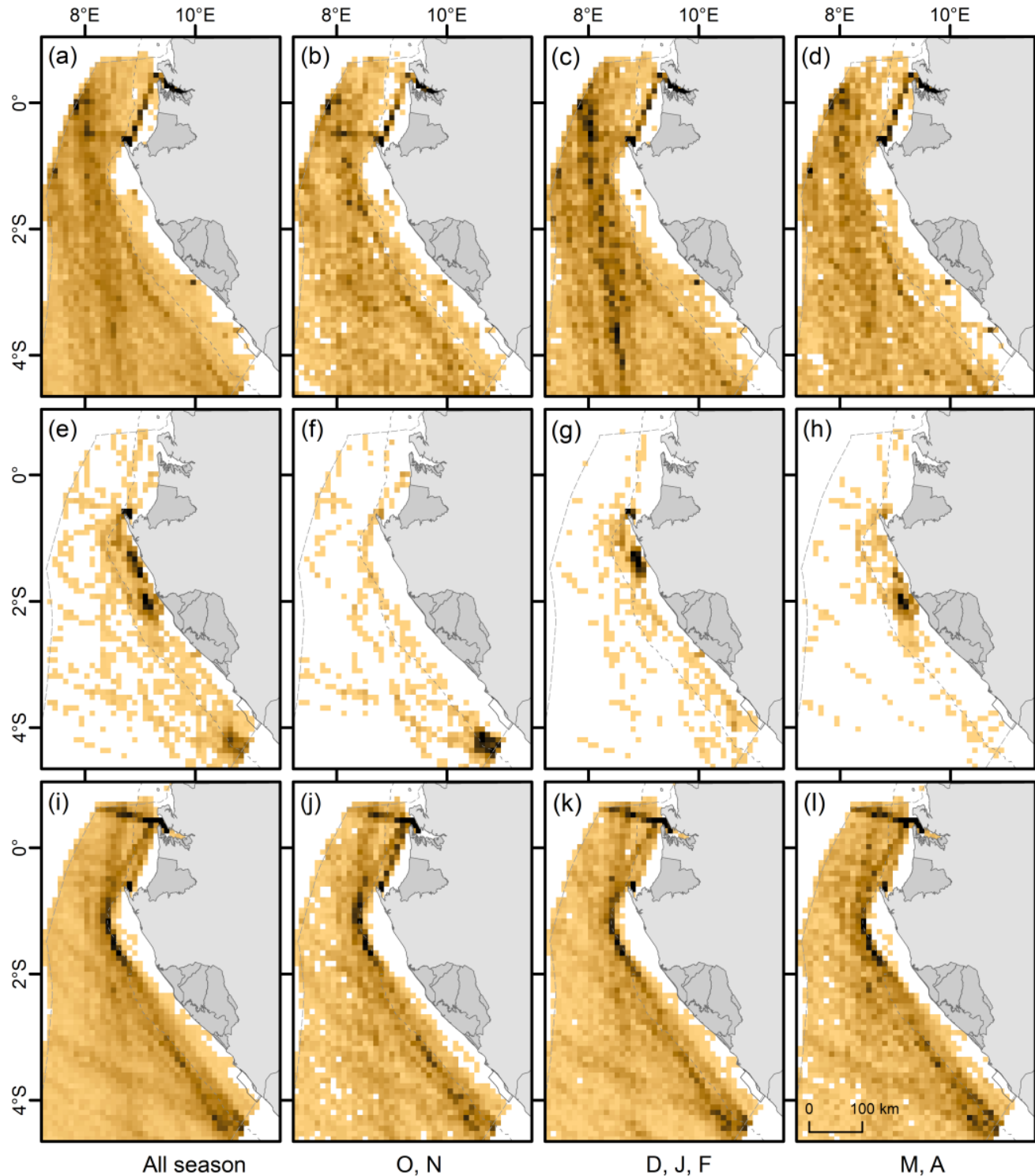

Oil

(a)

upport

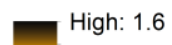

(b)

vessels da

Low: < 0.1

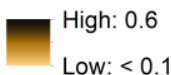

(c)

Seismic

(e)

research

vessels da

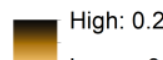

(n: mean)

Low: $<0.1$

Cargo

(n: mean)

(i)

High: 2.7

Low: $<0.1$

(f) Low: $<0.1$

High: 0.2

(j)

High: 0.9
Low: < 0.1

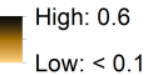

(g)

High: 0.2

(k)

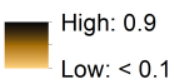

(d)

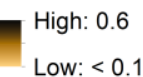

(h)

High: 0.2 Low: $<0.1$

(I) 


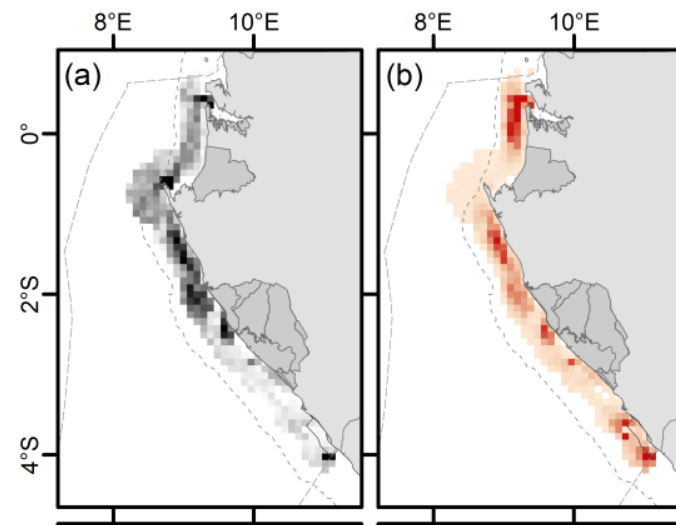

\section{All season}

Vessel density

(VMS \& AIS)

(a) (relative density)

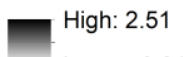

Low: $<0.01$

Leatherback

(b) threat index
High: 1.52
Low: $<0.01$

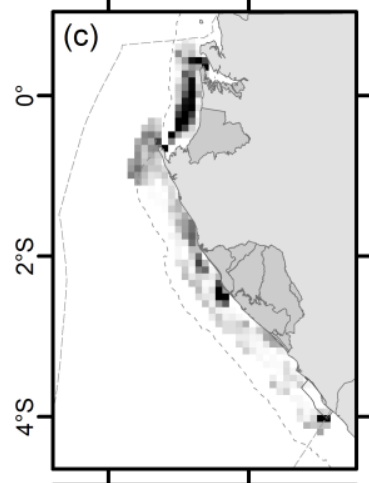

(d)

$\mathrm{O}, \mathrm{N}$

Vessel density

(VMS \& AIS)

(c) (relative density)

High: 1.78

Low: $<0.01$

Leatherback

(d) threat index

High : 0.15

Low: $<0.01$
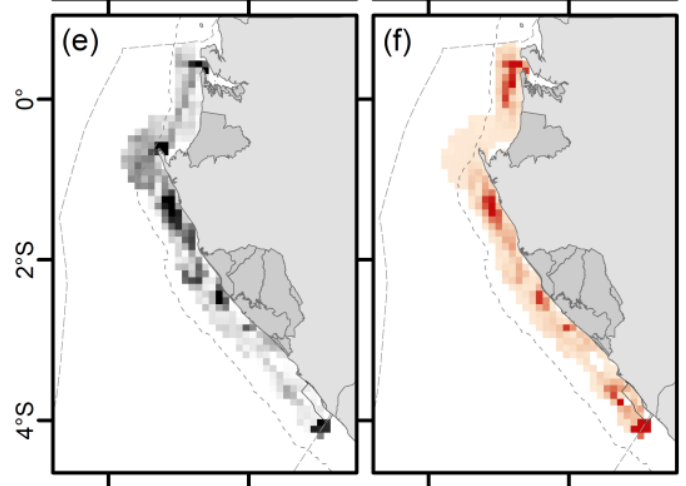

$D, J, F$

Vessel density

(VMS \& AIS)

(e) (relative density)

High: 2.23

Low: $<0.01$

Leatherback

(f) threat index

High: 1.39

Low: $<0.01$

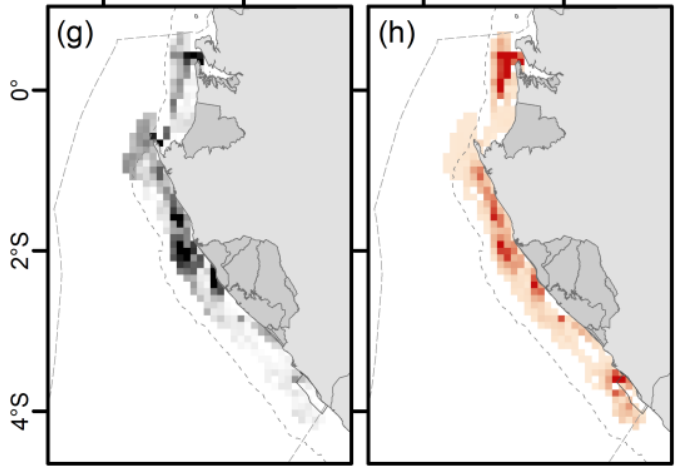

M, A

Vessel density

(VMS \& AIS)

(g) (relative density)

High: 1.97

Low: $<0.01$

Leatherback

(h) threat index

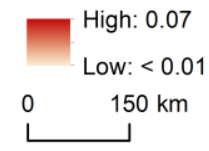


Fig. 5.

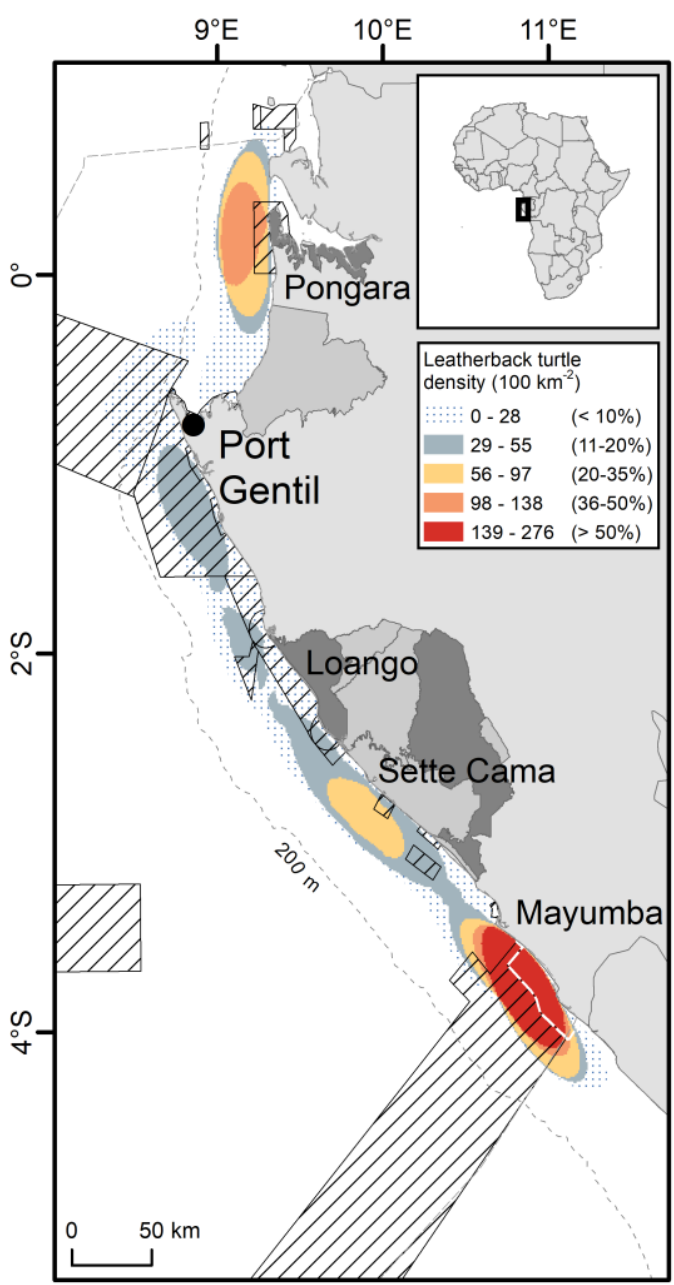

785 
787 Table A.1. Aerial survey schedule for the Gabonese coast 2002/03, 2005/06 and 2006/07.

\begin{tabular}{|c|c|c|c|}
\hline \multirow{2}{*}{$\begin{array}{l}\text { Nesting } \\
\text { season }\end{array}$} & \multirow[t]{2}{*}{ Survey } & \multicolumn{2}{|c|}{ Aerial survey dates } \\
\hline & & Start & End \\
\hline \multirow[t]{2}{*}{$2002 / 03$} & 1 & 2003-01-11 & 2003-01-12 \\
\hline & 2 & $2003-01-25$ & $2003-01-26$ \\
\hline \multirow[t]{3}{*}{ 2005/06 } & 1 & $2005-12-08$ & 2005-12-09 \\
\hline & 2 & $2006-01-23$ & $2006-01-25$ \\
\hline & 3 & 2006-02-21 & $2006-02-22$ \\
\hline \multirow[t]{3}{*}{ 2006/07 } & 1 & $2006-12-12$ & 2006-12-14 \\
\hline & 2 & $2007-01-25$ & $2007-01-26$ \\
\hline & 3 & $2007-02-23$ & 2007-02-24 \\
\hline
\end{tabular}

788 
789 Table A.2. Summary of PTT data for female leatherback turtles, detailing: PTT Id., nesting

790 season, release location, deployment date, inter-nesting periods (n), PTT manufacturer and

791 model.

792

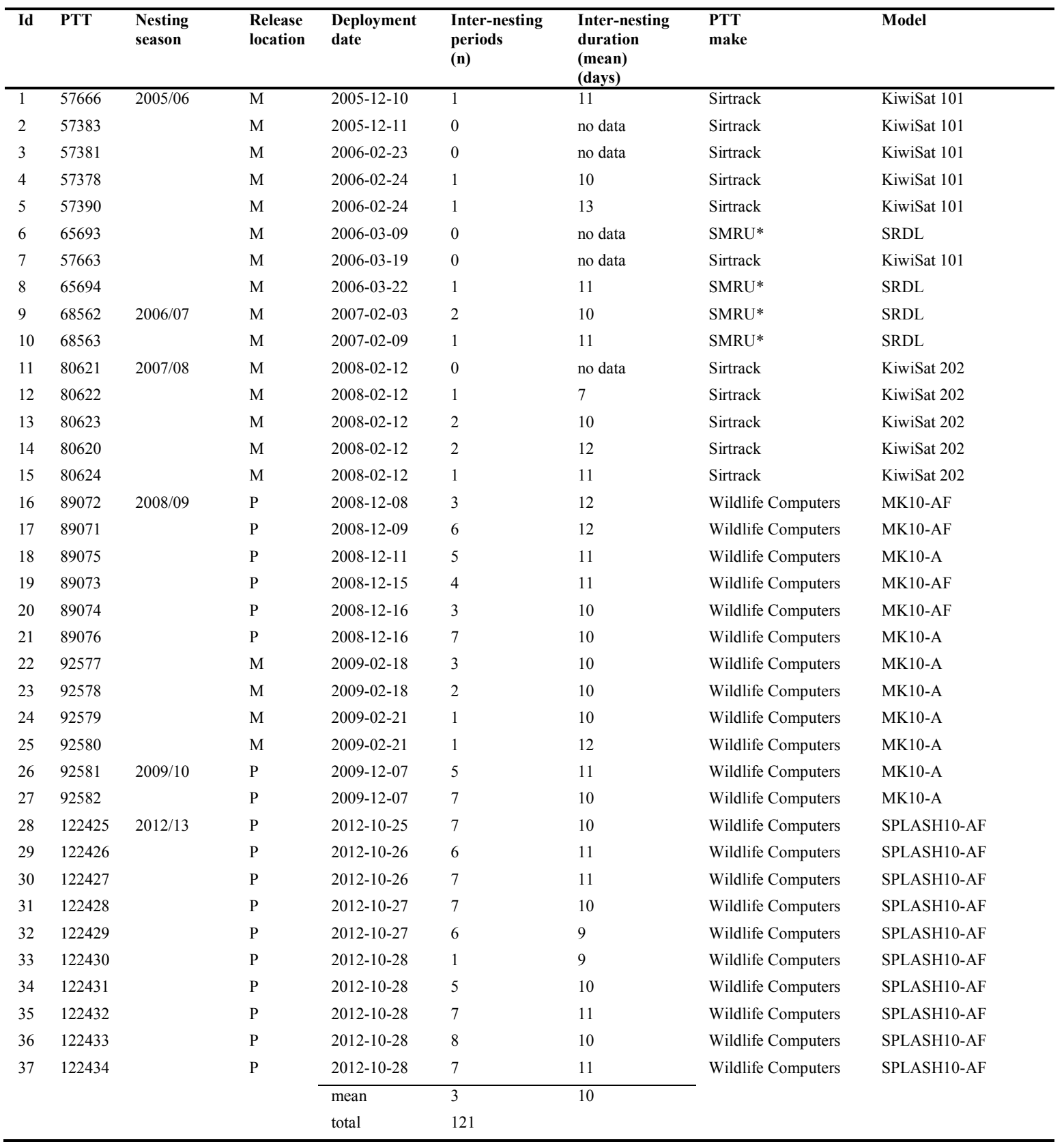

* Sea Mammal Research Unit 
794 Table A.3. Summary of output from Wilcoxon test of semi-major, semi-minor and offshore

795 distance for leatherback turtles between the nesting locations of Pongara and Mayumba National

796 Parks.

\begin{tabular}{lllll}
\hline Ellipse metric & Wilcoxon z score & p value & \multicolumn{2}{l}{ Median value (km) } \\
\cline { 3 - 5 } & & & Pongara & Mayumba \\
\hline Semi-major axis length & 1.29 & 0.20 & 36.25 & 45.19 \\
Semi-minor axis length & 0.23 & 0.82 & 16.74 & 17.80 \\
Offshore distance & 0.91 & 0.36 & 16.37 & 19.03 \\
\hline
\end{tabular}

797

798 